\title{
Smart Village sebagai Upaya Penguatan Kapasitas Pemerintahan Nagari
}

\author{
Kusdarini, Desna Aromatica, Ria Ariany, Hendri Koeswara, Muhammad Ichsan \\ Kabullah, dan Misnar Sitriwanti \\ Fakultas Ilmu Sosial dan Ilmu Politik, Universitas Andalas, Kampus Limau Manis, Padang, 25163. Indonesia \\ E-mail: kusdarini@gmail.com
}

Keywords: capacity, nagari government, smart village

Kata Kunci: kapasitas, pemerintah nagari, smart village

\begin{abstract}
The existence of the Nagari Government as the foremost government is expected to improve the welfare of the community. In 2016 the poverty rate in Solok Regency reached $10 \%$ of the total population of 363,684 people, where this poverty was caused by food poverty. Even though in 2017 the poverty rate decreased, poverty remains high. For this purpose, this community service activity aims to introduce innovative concepts in managing the nagari government so as to produce a module that can become a blueprint for a governance concept in the concept of smart villages. These two adjacent Nagari can support each other and become a pioneer for other nagari, especially the advanced nagari to rise at the Village level or Nagari with an independent village index. This activity cover several things, namely 1) Introduction of the concept of smart rural. 2) Identification of smart rural dimensions that have developed and need to be developed. The result of this activity was that in Nagari Selayo and Nagari Koto Baru, Kubung District is preparing to go to the smart village. There are still many steps that need to be done, especially related to the readiness of human resources and also Nagari Government institutions and also community participation. Because the key to the success of the realization of smart villages is the active involvement of all elements involved, with the support of qualified information technology (ICT).
\end{abstract}

\section{ABSTRAK}

Keberadaan Pemerintahan Nagari sebagai pemerintahan terdepan diharapkan dapat meningkatkan kesejahterakan bagi masyarakat. Pada tahun 2016 angka kemiskinan di Kabupaten Solok mencapai 10\% dari jumlah penduduk sebesar 363.684 jiwa, dimana kemiskinan ini disebabkan oleh kemiskinan pangan. Meskipun pada tahun 2017 angka kemiskinan menurun, namun kemiskinan tetap tinggi. Untuk itu kegiatan pengabdian ini bertujuan mengenalkan konsep inovatif dalam mengelola pemerintahan nagari sehingga menghasilkan modul yang dapat menjadi blue print sebuah acuan penyelenggaraan pemerintahan berkonsep smart village. Dua Nagari berdekatan ini dapat saling menopang dan menjadi pionir bagi nagari lain, khususnya nagari maju untuk naik pada level Desa atau Nagari dengan indeks desa mandiri. Kegiatan ini meliputi beberapa hal yaitu 1) pengenalan konsep smart rural. 2) identifikasi dimensi-dimensi smart rural yang sudah berkembang dan yang perlu dikembangkan. Hasil dari kegiatan ini adalah bahwa di Nagari Selayo dan Nagari Koto Baru Kecamatan Kubung sedang mempersiapkan diri untuk menuju smart village. Masih banyak langkah yang perlu dilakukan terutama berkaitan dengan kesiapan sumber daya manusia dan juga kelembagaan Pemerintahan Nagari dan juga partisipasi masyarakat. Karena kunci sukses terwujudnya smart village adalah dengan keterlibatan aktif seluruh elemen yang terkait, dengan dukungan teknologi informasi (ICT) yang mumpuni. 


\section{PENDAHULUAN}

Lahirnya Undang-Undang tentang Pemerintahan Daerah pada tahun 1999, hingga UndangUndang nomor 6 tahun 2014 tentang Desa, telah menguatkan kedudukan Pemerintahan Desa sebagai bagian dari Pemerintahan di daerah. Melalui Undang-Undang tersebut penyeragaman bentuk Pemerintahan Desa di seluruh Indonesia dihapus, sebagai bentuk pengakuan negara terhadap hak asal-usul dan adat-istiadat yang masih hidup dalam masyarakat Desa. Hal ini juga didasarkan pada harapan bahwa desa-desa akan berkembang mandiri dan sejahtera dengan caranya sendiri-sendiri sesuai kelokalitasannya.

Sumatera Barat adalah Propinsi yang sebelum diberlakukannya Pemerintahan Desa dan Kelurahan oleh Undang-Undang Nomor 5 Tahun 1979 Tentang Desa, telah memiliki Pemerintahan terdepan yaitu Pemerintahan Nagari. Penghapusan penyeragaman bentuk Pemerintahan Desa oleh Undang-Undang, menjadi momentum penyelenggaraan kembali Pemerintahan Nagari. Penyelenggaraan Pemerintahan Nagari diatur melalui Peraturan Daerah Provinsi Sumatera Barat nomor 9 Tahun 2000 Tentang Pokok-Pokok Pemerintahan Nagari, dan direvisi dengan Peraturan Daerah Provinsi Sumatera Barat no 2 tahun 2007 Tentang Pemerintahan Nagari.

Negara melalui regulasinya mendesain Pemerintahan Nagari dengan model Hybrid organization, yaitu percampuran antara self governing community terkait otonomi yang dimilikinya, dengan local self government, terkait kedudukannya sebagai penyelenggara urusan pemerintahan dan kepentingan masyarakat Desa. Kabupaten Solok adalah Kabupaten pertama yang menyelenggarakan Pemerintahan Nagari, melalui Perda Kabupaten Solok nomor 4 tahun 2001 tentang Pemerintahan Nagari. Komitmen terus berpemerintahan Nagari terlihat dari salah satu misi Pemerintah Kabupaten Solok dalam RPJMD Kabupaten Solok tahun 2016-2021, yaitu memantapkan penyelenggaraan pemerintahan yang baik dan bersih. Tujuan misi ini adalah mewujudkan penyelenggaraan pemerintahan nagari dan kelembagaan nagari. Sasaran dari tujuan ini adalah meningkatkan fasilitasi terhadap Pemerintahan Nagari dan kelembagaan Nagari, dengan strategi dan arah kebijakan adalah pelaksanaan fasilitasi dengan peningkatan kapasitas aparat dan kelembagaan Nagari.

Lembaga yang kuat akan membantu Pemerintah Nagari melaksanakan dan mencapai hasil maksimal, dalam tugas-tugas pembangunan yang dibebankan pada Nagari, yang tertuang dalam RPJM Nagari yang telah dirumuskan bersama masyarakat Nagari dan Rencana Kerja Pemerintah (RKP) Nagari. Menurut Antlov (2016), Undang-Undang Nomor 6 Tahun 2014 Tentang Desa, telah membuat Nagari memiliki ruang untuk membuat rencana pembangunan sendiri (one village one plan). Hal ini akan mendorong Nagari menjadi Nagari yang mandiri dan mampu mensejahterakan masyarakatnya.

Sepanjang 18 tahun telah menyelenggarakan Pemerintahan Nagari, dari tahun 2001 sampai dengan tahun 2018, keberadaan Pemerintahan Nagari yang diharapkan dapat meningkatkan kesejahterakan bagi masyarakat masih belum tercapai. Salah satunya persoalan kemiskinan. Data BPS 2015 angka kemiskinan Kabupaten Solok mencapai 9,04\% berada diatas angka kemiskinan Provinsi Sumatera Barat sebesar 6,71\%, bahkan di tahun 2016 angka kemiskinan di Kabupaten Solok mencapai 10\% (dari jumlah penduduk sebesar 363.684 jiwa) dimana kemiskinan ini disebabkan oleh kemiskinan pangan. Berdasarkan keputusan menteri Desa, Pembangunan daerah tertinggal dan transmigrasi RI nomor 030 tahun 2016 tentang status kemajuan dan kemandirian desa, hanya ada 3 nagari yang terkategori nagari maju (4,1\%), 36 Nagari berkembang (48,6\%), 29 Nagari tertinggal (39,2\%) dan 6 Nagari sangat tertinggal $(8,1 \%)$. Status kemandirian Desa ini menurut Peraturan Menteri Desa, Pembangunan Daerah Tertinggal dan Transmigrasi Republik Indonesia Nomor 2 Tahun 2016, menyatakan bahwa indeks ini ditentukan dari tiga (3) ukuran. Pertama adalah Indeks ketahanan sosial yang terdiri 
dari modal sosial, kesehatan, pendidikan dan pemukiman. Kedua adalah indeks ketahan ekonomi yang dilihat dari dimensi ekonomi. Ketiga Indeks ketahanan lingkungan yang terdiri dari dimensi ekologi.

Meskipun angka kemiskinan tinggi, namun masih ada Nagari maju yang dapat diberikan perhatian untuk mengembangkan pemerintahannya agar bergeser dari nagari maju ke nagari mandiri. Hal ini sesuai dengan tujuan UU no 6 tahun 2014 dimana penyelenggaraan pemerintahan Desa sesuai hak asal-usulnya diharapkan dapat meningkatkan kemandirian dan kesejahteraan Desa dan masyarakatnya. Smart village yang dikenalkan pada Nagari Koto Baru dan Nagari Salayo adalah bentuk bantuan referensi bagi Nagari-nagari maju ini untuk terus mengambangkan diri ditengah minimnya inovasi yang digagas pemerintah daerah. Maka sebagai akademisi administrasi publik konsep yang biasa diterapkan pada pemerintah daerah dan Kota ini dapat diadopsi di Nagari.

Nagari Salayo dan Nagari koto Baru berada pada satu kecamatan yaitu kecamatan Kubung. Uniknya, letaknya yang berbatasan sama-sama berada pada level indeks desa membangun pada tahap atau level desa atau nagari yang maju. Artinya ada satu level lagi yang harus dicapai agar amanat Undang-Undang nomor 6 tahun 2014 tentang Desa yaitu menjadikan Desa di Indonesia mandiri dan masyarakatnya sejahtera perlu dicapai. Sayangnya untuk naik ke level mandiri, Nagari ini tidak memiliki banyak referensi konsep dan pengalaman ditambah minimnya inovasi yang digagas pemerintah Kabupaten dalam upaya menjadi desa yang mandiri. Selama tahun 2016 hingga ke 2018 saja, hanya ada kurang lebih 11 kebijakan yang dihasilkan oleh pemerintah daerah terkait pengelolaan penyelenggaraan pemerintahan Nagari. Kebijakan yang dihasilkan juga hanya terkait persoalan asset dan teknis pengelolaan dana desa.

Kondisi ini kami yakini menjadi salah satu penyebab tidak kunjung naiknya level indeks membangun Nagari dari maju menjadi mandiri. Sebagai akademisi administrasi publik, pengenalan konsep model smart village, kami yakini dapat menjadi referensi penting bagi Pemerintah Nagari Koto Baru dan Nagari Salayo untuk terus berbenah mencapai level indeks desa membangun mandiri.

\section{METODE}

Berdasarkan permasalahan dan analisis situasi yang dihadapi mitra, diadakan beberapa kegiatan diantaranya adalah :

1. Pengenalan konsep smart village kepada Nagari Salayo dan Nagari Koto Baru. Merujuk pada konsep smart city oleh Giffiner, et al. (2007) bahwa smart village dalam konsep pengabdian ini adalah sebuah nagari yang terdepan ekonominya, sumber daya manusianya, pemerintahannya, mobilitas masyarakat dalam nagari, lingkungan, dan kehidupan masyarakatnya. Menurut Supangkat (2017), desa cerdas dapat diterapkan di Indonesia selama ada komunitas yang harus dilayani.

2. Identifikasi bersama Pemerintah Nagari dimensi-dimensi smart rural yang sudah ada dan berkembang dengan yang belum tergali dan belum dikembangkan. Identifikasi ini dilakukan untuk menentukan model smart rural masing-masing nagari. Menurut Ramachandra, dkk (2015), bahwa Desa yang mampu mencukupi kebutuhan sendiri dan tidak bergantung pada pihak lain (mandiri) dan memberdayakan masyarakatnya.

3. Merumuskan sebuah model smart rural berbasis karakteristik masing-masing Nagari yang kemudian dijadikan luaran berupa modul sebagai pedoman pengembangan smart rural di Nagari oleh Pemerintah Nagari. 
Metode pelaksanaan pengabdian kepada masyarakat, yaitu: pertama, persiapan. Tahap persiapan meliputi: 1) administrasi; 2) koordinasi dengan pihak khalayak sasaran (Pemerintah Nagari Salayo dan Nagari Koto baru), Badan Musyawarah Nagari Salayo dan Koto Baru; 3) penyiapan materi kegiatan pengabdian; 4) persiapan narasumber; 5) penyiapan waktu dan tempat pelaksanaan kegiatan; dan 5) checking terakhir. Kedua, pelaksanaan. Pelaksanaan kegiatan dalam bentuk sosialisasi/pengenalan dengan judul: Smart village Sebagai Upaya Penguatan Kapasitas Pemerintah Nagari, dengan khalayak sasaran adalah Pemerintah Nagari Koto Baru dan Nagari Salayo yang meliputi Wali Nagari dan perangkat Nagari, termasuk Badan Musyawarah Nagari.
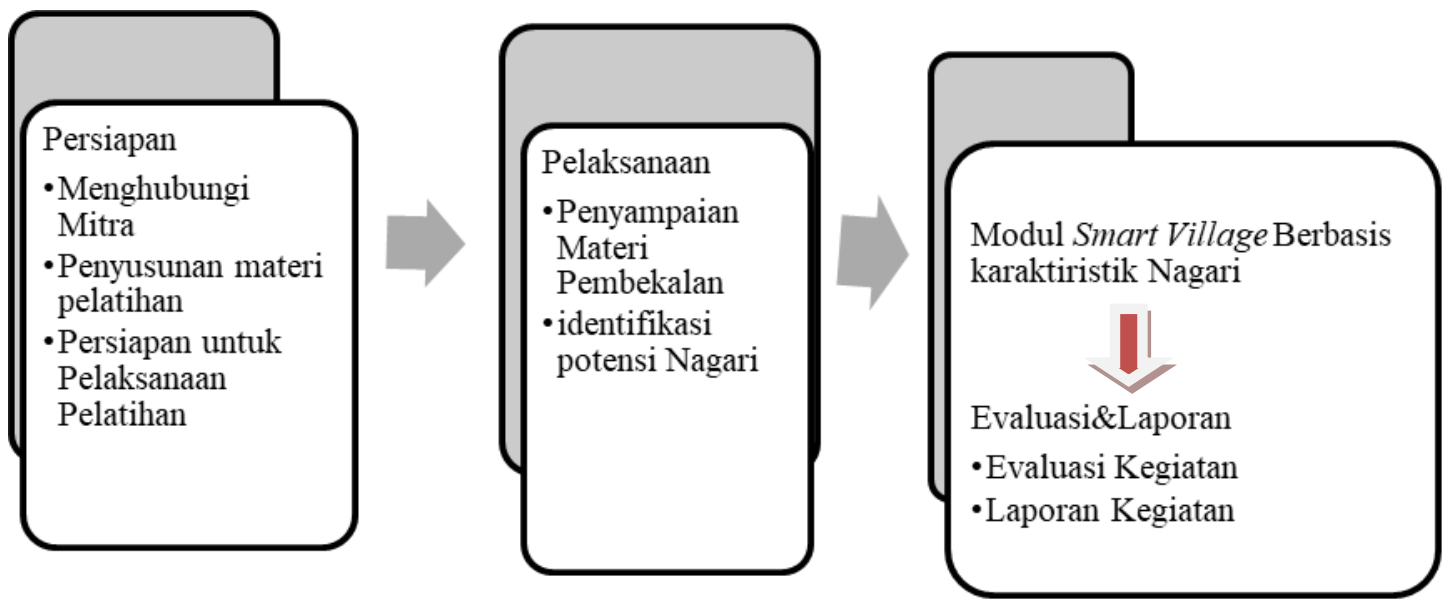

Gambar 1. Pelaksanaan Kegiatan

\section{HASIL DAN PEMBAHASAN}

Konsep Smart Village merupakan pengembangan dari konsep Smart City. Konsep smart city ini dinilai lebih relevan apabila dilaksanakan di kota daripada di desa/nagari. Hal ini disebabkan adanya perbedaan karakter antara kota dan desa, sehingga lahirlah konsep smart village yang diterapkan di desa/nagari. Dalam pelaksanaannya, konsep smart village ini harus didukung oleh beberapa komponen agar mampu memberikan dampak positif kepada masyarakat. Komponen tersebut antara lain Smart Institution, Smart Infrastructure, Smart Service Delivery, Smart Technology and Innovation, dan Smart Societis. Untuk menjalankan segala komponen tersebut dengan baik, dibutuhkan dukungan dan kerjasama yang baik satu sama lain. Organisasi sosial, petani, buruh, dan perusahaan-perusahaan kecil ataupun besar.

Penerapan konsep Smart Village dalam membangun desa tidak hanya berfokus pada penerapan kecanggihan teknologi di suatu desa, tetapi ada hal yang lebih utama, yaitu lebih kepada bagaimana konsep ini mampu mengubah kondisi masyarakatnya menuju keadaan yang lebih baik dan sejahtera, menumbuhkan kesadaran di masyarakat akan pentingnya sebuah inovasi dalam usaha kecil yang berpotensi untuk menciptakan kewirausahaan, dan meningkatkan kualitas pelayanan di desa agar lebih mampu memberikan kenyamanan dan kepuasan pada masyarakat. Selain itu, kunci dari suksesnya konsep Smart Village adalah dengan menambah pengetahuan masyarakat desa melalui pendidikan dan pengembangan keterampilan. Dengan adanya Smart Village ini, peran pemerintah desa akan lebih dioptimalkan dengan tujuan agar dapat mengelola sumberdaya desanya secara efektif, efisien, dan sustainable.

Pada Provinsi Sumatera Barat terdapat desa dan terdapat juga nagari, jumlah desa di Provinsi Sumatera Barat sejumlah 120 desa, 808 nagari. Jadi totalnya ada 928 desa dan nagari di 
Provinsi Sumatera Barat. Di Kabupaten Solok tersebar sebanyak 74 nagari. Karena permasalahan pembangunan dipedesaan sebagian besar merupakan permasalahan di bidang ekonomi, diantaranya : (1) Ketimpangan, (2) Kemiskinan dan (3) Urbanisasi. Untuk menjawab permasalahan tersebut perlu komitmen tinggi dalam penganggaran desa, makanya dibentuk Undang-undang Nomor 6 Tahun 2014 tentang Desa. Agar lebih kuat, pemerintah mengupayakan di desa itu ada bantuan keuangan desa dan pendampingan desa. Hasil penggunaan Dana Desa 4 (empat) Tahun terakhir diantaranya digunakan untuk :

1. Menunjang aktivitas ekonomi masyarakat

2. Meningkatkan kualitas hidup masyarakat

Pada Tahun 2019 masing-masing desa di Provinsi Sumatera Barat menerima Dana Desa sebanyak Rp. 1.004.000.000,-. Untuk pemanfaatan Dana Desa sebenarnya jangan hanya dimanfaatkan untuk fisik saja, tapi juga harus fokus pada pemberdayaan masyarakat juga. Mindset masyarakat harus dirubah agar Dana Desa itu tidak hanya untuk fisik saja, sehingga pentingnya ada inovasi desa yang prinsip pelaksanaanya adalah :

1. Kolaboratif

2. Transparan

3. Keberlanjutan

4. Partisipatif

5. Kesetaraan dan keadilan gender

Selain itu, pemanfaatan Dana Desa juga digunakan utuk kesejahteraan masyarakat dan pelayanan publik dengan dituntutnya desa melakukan inovasi agar melahirkan smart government pada smart village yang transparan serta dipublikasikan. Tujuanya adalah untuk :

1. Meningkatkan kreativitas dan inovasi serta motivasi wali nagari/kepala desa

2. Mengevaluasi, menilai dan mendorong bupati/walikota untuk mengoptimalkan Dana Desa

3. Sebagai apresiasi terhadap wali nagari/kepala desa atas pengelolaan dana desa

Pada kasus yang terjadi di Pemerintah Nagari Kotobaru dan Pemerintah Nagari Selayo sendiri, struktur pemerintahan nagari dibuat ramping dimana sekretariat diisi sebanyak sepuluh sampai lima belas orang. Jumlah ini masih tergolong ramping mengingat pada beberapa kasus, masih banyak ditemukan pemerintah desa yang memiliki jumlah anggota lebih dari dua puluh orang. Sedikitnya jumlah pegawai yang menangani pelayanan di Pemerintah Nagari Kotobaru dan Pemerintah Nagari Selayo karena masing-masing nagari tersebut telah menggunakan teknologi dalam pelayanan.

Hal lain yang juga perlu dilakukan adalah kegiatan berbasis perencanaan yang matang. Sebagaimana yang diamanatkan UU Nomor 6 Tahun 2014 tentang Desa, pemerintah desa atau nagari diamanatkan untuk menyelesaikan persoalan kemiskinan dan menahan laju urbanisasi. Berangkat dari hal tersebut, Pemerintah Provinsi Sumatera Barat sendiri telah menganggarkan program/ kegiatan yang cukup besar bagi pemerintah nagari. Tercatat dari kurun waktu 2015 sampai 2019, Pemerintah Provinsi Sumatera Barat telah menganggarkan sampai Rp. 3,35 Triliun (Badan Pemberdayaan Masyarakat Desa dan Nagari Provinsi Sumatera Barat, 2019). Di tahun 2019, setiap nagari rata-rata menerima kurang lebih Rp. 1,04 Milyar Badan Pemberdayaan Masyarakat Desa dan Nagari Provinsi Sumatera Barat, 2019). Dengan jumlah anggaran yang besar tersebut, Pemerintah Nagari Kotobaru dan Pemerintah Nagari Selayo dituntut memiliki rencana kerja yang jelas sesuai dengan kebutuhan masyarakatnya. Untuk itu, sebagian besar anggaran dialokasikan untuk sektor pemberdayaan masyarakat. Hal ini sangat berbeda jauh dengan fenomena mayoritas desa atau nagari yang masih memfokuskan belanja pada sektor infrastruktur. Besarnya anggaran untuk sektor pemberdayaan dikarenakan Nagari Kotobaru dan Nagari Selayo telah diklasifikasikan sebagai nagari maju. Untuk itu, ruang fiskal pemerintah kedua nagari tersebut sesungguhnya cukup besar untuk membuat kegiatan yang inovatif seperti pelayanan berbasis elektronik. 
Pemanfaatan layanan pemerintah nagari berbasis elektronik bukanlah hal yang sukar dilakukan ditengah zaman disrupsi teknologi saat ini. Untuk itu, Pemerintah Nagari Kotobaru dan Pemerintah Nagari Selayo telah mencoba mendorong layanan berbasis elektronik dengan mempelajari best practice yang ada di Desa Pematang Johar, Kecamatan Labuhan Deli, Kabupaten Deli Serdang pada Desember 2019. Dari studi banding yang dilakukan, perangkat Pemerintahan Nagari Kotobaru dan Pemerintahan Nagari Selayo telah bersepakat untuk membuat layanan berbasis elektronik pada tahun 2020. Hal yang masih menjadi kendala adalah minimnya tenaga IT untuk melakukan maintenance apabila ditemukan gangguan di lapangan.

Hal lain yang menjadi salah satu kebanggaan Nagari Selayo adalah Pemerintah Kabupaten Solok, Sumatera Barat, mengajukan Nagari Selayo, Kecamatan Kubung menjadi salah satu Kampung Wisata Budaya setelah sebelumnya berhasil mengorbitkan Nagari Jawi-Jawi Guguak sebagai Kampung Budaya Pengajuan kampung wisata budaya Nagari Selayo ini akan lebih diarahkan kepada keunggulan adat istiadat, dan usaha ekonomi kreatif yang dikembangkan Kelompok Sadar Wisata (Pokdarwis).

Selain menonjolkan tatanan adat masyarakat, Nagari Selayo juga memiliki usaha ekonomi kreatif yakni sulam benang merah yang merupakan motif sulam khas daerah itu, dan kini cukup berkembang. Nagari Selayo juga memiliki situs sejarah dan budaya yang erat kaitannya dengan sejarah perjalanan daerah seperti makam Datuk Parpatih Nan Sabatang. Dari sejumlah potensi yang sudah didata Dinas Pariwisata, nantinya akan dipilih mana yang bisa diadopsi sesuai potensi sumber daya lokal dan kearifan lokal masyarakat di Nagari Selayo, baru kemudian dikembangkan.

Langkah ini akan menjadi salah satu poin penting dalam pengembangan kapasitas pemerintah nagari khususnya Pemerintah Nagari Salayo dalam mencapai perwujudan smart village di Kecamatan Kubung Kabupaten Solok.

Dengan adanya smart government pada smart village diharapkan :

1. Pemerintah nagari/desa yang pelaksanaannya sesuai dengan potensi dan permasalahan yang ada di desa (hasil musrenbang).

2. Pelaksanaan kegiatan di desa dilakukan transparan dan selalu ada pembinaan dari bupati dan walikota.

3. Meningkatnya kepercayaan masyarakat terhadap nagari.

4. Partisipasi masyarakat dalam pembangunan nagari/desa akan meningkat.

5. Kontrol masyarakat terhadap pelaksanaan pembangunan di desa/nagari akan tercipta.

Dengan model ini diharapkan akan tercipta nagari/desa yang mandiri dan akuntabel. Dari apa yang sudah dilakukan oleh Pemerintah Nagari Koto Baru dan Nagari Selayo, dapat digunakan Model smart village /smart rural yang dikembangkan seperti berikut :

Sumberdaya (Manusia, Teknologi,SDA)

Institusi yang kuat

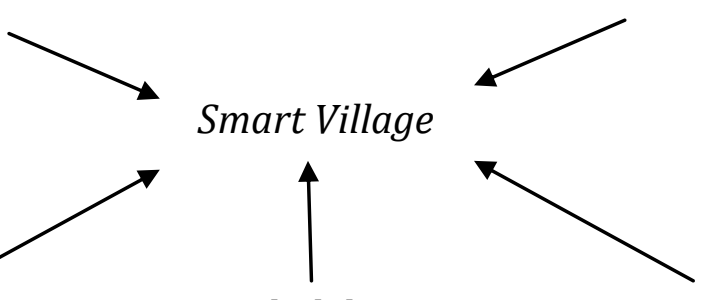

Teknologi yang bersahabat Konsep kolaborasi Berkelanjutan

Gambar 2. Model Smart Village 


\section{KESIMPULAN}

Berdasarkan pada realita bahwa nagari/desa juga menjadi tumpuan pembangunan nasional, dan keberhasilan desa secara akumulatif akan mendorong kelangsungan ekonomi nasional maka posisi nagari/desa menjadi sungguh sangat penting. Nagari/Desa perlu dikembangkan secara inovatif menuju desa cerdas atau smart village.

Untuk mencapai smart village, dibutuhkan usaha yang lebih besar dengan peningkatan dan pengembangan nagari/desa, ketersediaan infrastruktur yang ada, serta kecukupan resources yang memadai. Selain itu, dalam upaya mewujudkan smart village ini harus didukung dengan partisipasi seluruh elemen masyarakat dan juga lembaga terkait untuk mewujudkan smart institution, smart infrastructure, smart service delivery, smart technology and innovation, serta smart societies. Untuk memenuhi seluruh komponen tersebut, diperlukan dukungan seluruh ekosistem smart village yang berpengaruh . Puluhan organisasi perlu untuk berkolaborasi lintas industri/sektor untuk membangun sebuah smart village. Ini termasuk melibatkan perusahaanperusahaan yang memiliki kapasitas teknologi, pemerintah daerah, litbang akademik, organisasi sosial, perusahaan besar dan kecil, petani, buruh, dll. Banyak dari organisasi ini berada di luar ekosistem desa, namun relatif cukup memiliki pengaruh untuk terlibat dalam program smart village.

Membangun smart village atau nagari cerdas tidak hanya semata-mata terbatas pada kecanggihan ICT (Information Communication and Technology) saja, tetapi yang lebih utama dan perlu ditekankan adalah bagaimana konsep smart village ini bisa mengubah kapasitas masyarakatnya dan cara mereka berinteraksi. Menciptakan kesadaran diantara warga desa tentang pentingnya inovasi dalam usaha mikro dan kecil untuk menciptakan kewirausahaan adalah hal penting.

Smart village atau kampung cerdas akan mendesain nagari/desa sebagai pusat kreativitas warga yang menggabungkan antara kegiatan ekonomi produktif dan kreatif, peningkatan pendidikan dan kesehatan, upaya pengentasan kemiskinan, dengan instrumen ICT sebagai pendorongnya. Contohnya penunjukan Nagari Salayo sebagai Kampung Wisata. Dengan penerapan konsep smart village ini, peran pemerintah nagari lebih dioptimalkan agar dapat mengelola sumberdaya yang dimiliki oleh nagari dapat dikelola secara efektif, efisien, dan berkelanjutan.

\section{UCAPAN TERIMA KASIH}

Dalam kesempatan ini, penulis menyampaikan ucapan terima kasih kepada LPPM Universitas Andalas yang telah berkenan memberikan kesempatan melakukan kegiatan pengabdian masyarakat kepada Jurusan Administrasi Publik, Pemerintahan Kecamatan Kubung, Pemerintahan Nagari Koto Baru dan Pemerintahan Nagari Selayo, dan tidak lupa untuk Dinas Pemberdayaan Masyarakat Pemerintah Provinsi Sumatera Barat. 


\section{DAFTAR PUSTAKA}

Andari, Rosita.Novi dan Susy Ella. 2019. Pengembangan model smart rural untuk pembangunan Kawasan Perdesaan di Indonesia. Jurnal Borneo administrator Vol I (15) p. 41-58.

Giffinger,R.,Fertner C.,Kramar.,H.,Kalasek.,R. Natasa.,P.-M.,and Meijers,E. 2007. Smart cities: Rangking of European medium-sized cities. October, https://doi.org/10.1016/s0921503(00)00781-4.

Supangkat. 2015. Pengenalan dan Pengembangan Smart City. Bandung:e-Indonesia Initiatives. Intitute Teknologi Bandung.

Undang-Undang Nomor 6 Tahun2014 tentang Desa. 